\title{
Sexually transmitted diseases in Nigeria
}

\author{
R D CATTERALL \\ From James Pringle House, the Middlesex Hospital, London
}

\section{Background}

Nigeria is a young, rapidly developing country. Its boundaries were drawn by the British in 1900 but it has only been independent since 1960 . Its surface area is about four times that of Great Britain and it has an estimated population of between 80 and 100 millions. Geographically it can be divided into four zones. The coastal belt includes extensive sandy beaches, behind which are mangrove swamps. Thick tropical rain forests extend inland for over 100 miles to give way to a grassy savannah alternating with tree-covered parkland. The north is continuous with the Sudan savannah zone and merges into the Sahara desert. The main activity of the people throughout Nigeria is farming.

The climate ranges from equatorial in the south to tropical in the middle zones and arid in the north. Temperatures are high. On the coast there is little variation from 28 to $30^{\circ} \mathrm{C}$ with a relative humidity of over $70 \%$ whereas in the north, in the dry season, temperatures may reach $43^{\circ} \mathrm{C}$ during the day and fall to $4^{\circ} \mathrm{C}$ at night. The humidity will average about $30 \%$.

Rainfall is seasonal. The dry season varies from three months in the south to six months in the north. The rainfall decreases from south to north so that Lagos, on the coast, receives over $2000 \mathrm{~mm}$ a year whereas Sokoto in the north has about $690 \mathrm{~mm}$.

Nigeria is the most highly populated state in Africa and the ninth most populous in the world.

\section{THE PEOPLE}

There are more than 250 ethnic groups, as the area was one of the focal points of the many large population movements in Africa. The largest groups are the Hausa, principally in the north, the Yoruba, in the south-west, and the Ibo, in the south east, who together make up $70 \%$ of the total. The population has been increasing very rapidly but accurate figures are difficult to obtain. The south of the country is much more densely populated than the north.

Address for reprints: Dr R D Catterall, James Pringle House, the Middlesex Hospital, London W1N 8AA

Received for publication 16 October 1979
Urbanisation has been occurring at a phenomenal rate and the number and size of cities has increased rapidly, associated with recent economic development and increasing prosperity.

For administrative purposes the country is divided into 19 states. Lagos is the federal capital, and Nigeria's main port, as well as being the centre for industrial, commercial, and financial affairs. Its population is well over three million and it is said to be one of the fastest growing cities in Africa. Recently the government has announced that the capital is to be transferred from Lagos to a new site in the centre of the country.

The second largest city in Nigeria is Ibadan, with a population of well over two million inhabitants. It is an important industrial centre situated in the middle of a cocoa-producing area and has a well known university. Kano is the largest town in the north and is an ancient trading centre with rapidly growing modern industry, including a motor-car assembly plant.

English is the official, commercial, and main cultural language. It is the medium of education at all levels. About $45 \%$ of the population are Muslim, predominantly in the north, over $30 \%$ are Christian (divided between Catholics, Protestants, Methodists and Presbyterians), mainly in the south, and some of the remainder follow a variety of traditional beliefs.

\section{THE GOVERNMENT}

On 1 October 1963, Nigeria became a federal republic within the Commonwealth. In 1966 there was a military coup and several leading politicians were massacred. From 1967 to 1970 there followed a terrible civil war with uncontrolled killings and starvation. After the war a military government remained in office and the present regime has arranged to return power to a civilian government in October 1979 after new elections.

\section{LEGAL SYSTEM}

The legal system is based on English law. There is a federal supreme court, presided over by the Chief Justice, which is the final court of appeal. It has power to interpret the Constitution and hears disputes over legal rights between state governments, 
or between a state and the federal government. Each state has a high court. As in Britain, the magistrates courts have jurisdiction in a wide variety of civil and criminal cases.

\section{ECONOMY}

Agriculture was the basis of the Nigerian economy until recently and still provides a livelihood for nearly $70 \%$ of the population. The main crops are cocoa, groundnuts, cotton, rubber, and palm produce, and the main food crops are rice, maize, guinea corn, millet, and yams. Nigeria is the world's largest producer of cocoa and the largest producer of rubber in Africa. Oil was first discovered in 1956 and the rate of production increased rapidly in the ensuing 24 years. Nigeria is now the world's seventh largest oil producer and the largest in Africa. Most of it is found in the delta of the River Niger and in the offshore fields. Natural gas, coal, tin, and iron ore are other riches found in the country, which could secure its economic progress well into the next century.

\section{EDUCATION}

Education has a long tradition of Christian missions in the south whereas in the north there is a strong Islamic tradition. Government policy is aimed at providing free, universal, and compulsory primary education in all areas. Nearly all secondary schools are fee-paying. In 1960 there were two universities but by 1979 there were 12 . The oldest is the University of Ibadan, which was originally constituted in 1948 as a college affiliated to the University of London.

The illiteracy rate however is still high in Nigeria and is believed to affect about $75 \%$ of the population, in spite of literacy programmes. The government is trying to involve young people in the development of the country as a whole and has launched a National Youth Service Corps which qualified students must join. They are sent to all parts of the country to teach, do medical work, or organise voluntary labour.

\section{HEALTH CARE}

Most tropical diseases are endemic in Nigeria. The prevalent diseases are malaria, tuberculosis, dysentery, meningitis, measles, and tetanus. Other major health problems are hepatitis $\mathbf{A}$, intestinal parasites, trypanosomiasis, onchocerciasis, and sexually transmitted diseases. Leprosy is still common but yaws now appears to be rare.

Public health facilities, including hospitals and clinics, are run by the states although there are a few federal institutions. Government health facilities are free to government employees and are inexpensive to everyone else. The current plan is to try to achieve a more equitable distribution of health services, which only reach about $50 \%$ of the population. It is planned to establish 285 basic health units throughout the country.

Patients have to pay for medical consultations, investigations, and treatment. There are some general practitioners, mostly in the urban areas, but many patients just turn up at a hospital. They are interviewed by a fee collector who assesses how much the patient can afford to pay and are then sent to a sorting room to be assigned to a clinic.

Patients who are to be admitted to hospital have to deposit 100 Naira (about $\mathrm{f60}$ ) and usually have to pay about 20 Naira a day. Paupers and those unable to pay are treated free of charge.

The hospital service is financed by the state departments of health and the university hospitals by the Ministry of Education. Many of the university hospitals are very new or just developing. There is a shortage of general hospitals and of state-sponsored specialist hospitals. In many of these there may be over 500 new outpatients every day and one doctor may see as many as 90 patients a day.

Outside the main cities there are district hospitals with 30 to 40 beds and one doctor. An increasing number of health centres and dispensaries with nurses and attendants are being developed.

The British left behind them a number of mission hospitals, which are highly regarded, and there are an increasing number of private clinics and hospitals run by private doctors and commercial firms. In more outlying areas there are some mobile dispensaries. The St Johns Ambulance Brigade is active in Nigeria and there is a Nigerian Red Cross Society.

Taking the country as a whole, most patients are treated with traditional remedies and medicines, but an increasing number treat themselves with antibiotics and other modern drugs, which are freely available to everyone over the counter of chemists shops, in markets, and from merchants. Most have had some type of self-medication before they consult a doctor or go to a hospital.

\section{Sexually transmitted diseases}

There are only four clinics for patients with sexually transmitted diseases in the whole of Nigeria for a population of nearly 80 million people. They are in Ibadan, Lagos, Enugu, and Zaria.

The prevalence of sexually transmissible infections is unknown but is believed to be high, especially in the rapidly developing new towns. Self-treated patients probably form the largest group but in the rural areas traditional remedies are known to be popular. Inadequate treatment is the rule, but provided the symptoms are controlled most patients 
seem satisfied. This is probably an important factor in the development of $\beta$-lactamase-producing strains of gonococci in West Africa.

In the University College Hospital special clinic in Ibadan, non-specific urethritis is the commonest disease to be diagnosed, followed by gonorrhoea, trichomoniasis, and syphilis. Vaginal candidosis is diagnosed less frequently than in Britain, but the other sexually transmitted diseases are seen with a similar distribution to other countries.

Immediate Gram-stained smears are available and cultures are performed on selective media. The Venereal Disease Research Laboratory test and Treponema pallidum haemagglutination assay are used for serological investigation and Trichomonas vaginalis is looked for in a wet preparation. Darkground microscopy is also readily available.

Treatment schedules are similar to those used in Britain but benzathine penicillin is used exclusively in the treatment of syphilis in all stages. Chancroid is usually treated with sulphonamides and lymphogranuloma venereum with tetracyclines.

Contact tracing is enthusiastically carried out despite enormous difficulties. Casual contacts, reluctance to reveal names, unnamed streets, unnumbered houses, and the rapid movement of the population provide many problems. Nevertheless, the clinic is run efficiently and has an atmosphere resembling a busy active centre in Britain.

Patients with sexually transmitted diseases are frequently seen in general and specialist medical and surgical clinics as well as in private practice. They are usually treated with antibiotics without an accurate diagnosis; no contact tracing is attempted and no follow-up visits are arranged.

To test the market, personal experience is often best. In a large market in the centre of Ibadan I approached a merchant who was surrounded by remedies for all types of human ailments. I told him I had a discharge and that I thought it might be gonorrhoea and asked him what he recommended. Without hesitation he put his hand in his pocket and produced four black and red capsules which he offered to me. The price was 2 Naira each capsule (about f1) and I was instructed to take all the capsules at once. When I suggested that I might need more than four capsules, I was told that four were quite enough and I was reassured in a confident and convincing manner. When I said that I should like to seek another opinion, I was told it was quite unnecessary and my reception became decidedly less friendly.

\section{The Future}

Nigeria is a vast heavily populated country which is developing and changing at a phenomenal rate. The wealth resulting from the rapid increase in production of oil has been used for many prestige developments such as public buildings, universities, large well equipped armed forces, and rapid industrial expansion. There are however serious flaws in the present structure of the country because so many of the public services do not work. Powercuts are frequent, telephones do not function, telegrams take weeks to be delivered, the roads are full of pot-holes and are not maintained, there are serious delays in administrative action, and bribery is widespread in all walks of life.

Much of this is not surprising when the speed of change since independence only 19 years ago is taken into account. The medical services have expanded enormously but it must be remembered that this is an area of Africa with serious indigenous diseases, such as malaria, intestinal parasites, and trypanosomiasis. There is not yet a safe drinking-water supply in urban or country areas and sewage disposal is primitive and often non-existent. A great deal of basic preventive medicine remains to be done and has become urgent as a result of the rapid growth of the towns throughout the country.

As far as the sexually transmitted diseases are concerned, there is no doubt that they are very common, and many new factors-such as greater freedom for women, the increasing use of non-occlusive contraceptives, greater mobility with more frequent travel, and the absence of a nationwide network of clinics-must all result in a further increase in their prevalence and in greater problems resulting from the complications of inadequately treated diseases and the absence of contact tracing.

Nevertheless, a start has been made and the model clinic at University College Hospital, Ibadan, created by Professor A O Osoba, has now been copied at three other university centres. The pattern that is emerging is that the clinic is part of the department of medical microbiology and the clinics are staffed by members of that department, who are also responsible for the microbiological and serological support service. Trainees are normally sent to Britain for postgraduate training, and to obtain diplomas in microbiology and venereology, after adequate experience at home. This type of organisation may well be the best solution to the problem until it is economically possible to establish a separate service for patients with sexually transmitted diseases run by physicians with specialist training and devoting all their time to the specialty.

The rest of the world will watch the development of Nigeria and other West African countries with sympathy, understanding, and some anxiety, because of the regular export of $\beta$-lactamase-producing 
strains of gonococci to the outside world. No country wants to be a bad neighbour, but if it is exporting antibiotic-resistant strains of micro-organisms to its friends and neighbours, it may quickly earn that reputation. The problem is urgent and appears to be increasing in magnitude. There are signs however that since the very successful First African International Conference on Sexually Transmitted Diseases held in Ibadan in August 1979 governments and health authorities in Africa are more aware of the situation and may be prepared to allocate greater resources to try to contain these infections. 